\begin{tabular}{|c|c|c|c|}
\hline \multirow{3}{*}{$\begin{array}{r}\text { Case Reports in } \\
\text { Gastroenterology }\end{array}$} & \multirow{2}{*}{\multicolumn{2}{|c|}{ Case Rep Gastroenterol 2017;11:488-493 }} & \multirow[b]{3}{*}{$\begin{array}{l}\text { Karger } \\
\text { Open access }\end{array}$} \\
\hline & & & \\
\hline & $\begin{array}{l}\text { DOI: } 10.1159 / 000479497 \\
\text { Published online: August 17, } 2017\end{array}$ & \begin{tabular}{|l} 
(c) 2017 The Author(s) \\
Published by S. Karger AG, Basel \\
www.karger.com/crg
\end{tabular} & \\
\hline & $\begin{array}{l}\text { This article is licensed under the } \\
\text { International License (CC BY-NC) } \\
\text { Usage and distribution for commer }\end{array}$ & $\begin{array}{l}\text { mons Attribution-NonCommercial } 4.0 \\
\text { rger.com/Services/OpenAccessLicense). } \\
\text { quires written permission. }\end{array}$ & \\
\hline
\end{tabular}

\title{
Hemorrhagic Cholecystitis in a Patient on Maintenance Dialysis
}

\author{
Masayuki Shishida $^{a} \quad$ Masahiro Ikeda $^{a} \quad$ Nozomi Karakuchi ${ }^{a}$ \\ Kosuke Ono ${ }^{a}$ Naofumi Tsukiyama ${ }^{a}$ Manabu Shimomura ${ }^{a}$ \\ Koichi Oishi $^{\mathrm{a}}$ Kazuaki Miyamoto $^{\mathrm{a}}$ Kazuhiro Toyota $^{\mathrm{a}}$ \\ Seiji Sadamoto $^{a}$ Tadateru Takahashi $^{a, b}$ \\ ${ }^{a}$ Department of Surgery, National Hospital Organization Higashihiroshima Medical \\ Center, Higashihiroshima, Japan; ${ }^{b}$ Department of Gastroenterological and Transplant \\ Surgery, Applied Life Sciences, Institute of Biomedical and Health Sciences, Hiroshima \\ University, Hiroshima, Japan
}

\section{Keywords}

Hemorrhagic cholecystitis · Hemobilia · Dialysis

\begin{abstract}
The present paper describes a case of hemorrhagic cholecystitis in a patient on maintenance dialysis. The patient presented with right upper quadrant abdominal pain. Computed tomography revealed swelling of the gallbladder, high- and isodensity contents of the gallbladder, and high-density stone in the gallbladder neck. He was hospitalized for suspected acute cholecystitis. After hospitalization, his levels of total bilirubin, aspartate aminotransferase, and alanine aminotransferase increased. T2-weighted magnetic resonance imaging showed lowintensity contents expanded to include a wide area from the common bile duct to the cystic duct and gallbladder neck. Endoscopic retrograde cholangiopancreatography revealed clotting from the duodenal papilla. After cannulation of the bile duct, old blood and pus began to flow from the mammary papilla, and an endoscopic nasobiliary drainage tube was placed. After his liver function had improved, the patient underwent laparoscopic cholecystectomy. His sample revealed that the gallbladder was filled with blood clots and stones. His postoperative course was uneventful and he was discharged on day 19 after the procedure. Although hemorrhagic cholecystitis is rare, it should be considered as a differential diagnosis for patients on dialysis who have acute abdominal symptoms.
\end{abstract}




\section{Case Reports in Gastroenterology}

Case Rep Gastroenterol 2017;11:488-493 DOI: $10.1159 / 000479497$

(C) 2017 The Author(s). Published by S. Karger AG, Basel www.karger.com/crg

Shishida et al.: Hemorrhagic Cholecystitis in a Patient on Maintenance Dialysis

\section{Introduction}

Uremic bleeding is a well-known clinical condition in patients on dialysis; bleeding from the gallbladder, however, is very rare. Hemorrhagic cholecystitis is a rare disease characterized by hematemesis, upper abdominal pain, and obstructive jaundice [1]. Bleeding from the gallbladder can be caused by iatrogenic factors, inflammation, tumor, or injury [2]. The goal of treatment for hemobilia is to improve hemostasis and flow of bile secretion. For hemobilia due to hemorrhagic cholecystitis, cholecystectomy should also be performed. Here, we report a case of hemorrhagic cholecystitis in a patient on maintenance dialysis.

\section{Case Report}

A 79-year-old man who had received maintenance dialysis for type II diabetes-related chronic renal failure for approximately 2 years developed right upper quadrant abdominal pain after lunch and was taken to the hospital, where he received maintenance dialysis by ambulance. He had hypertension and a history of surgery for spinal canal stenosis and was receiving cilostazol as an antiplatelet agent. When he was taken to the hospital by ambulance, his blood test results were as follows: white blood cell count $5,160 / \mathrm{mm}^{3}$, hemoglobin $12.1 \mathrm{~g} / \mathrm{dL}$, platelet count $166,000 / \mathrm{mm}^{3}$, total bilirubin $0.77 \mathrm{mg} / \mathrm{dL}$, aspartate aminotransferase $125 \mathrm{IU} / \mathrm{L}$, alanine aminotransferase $52 \mathrm{IU} / \mathrm{L}$, blood urea nitrogen $70.1 \mathrm{mg} / \mathrm{dL}$, creatinine $7.76 \mathrm{mg} / \mathrm{dL}$, sodium $137 \mathrm{mEq} / \mathrm{L}$, potassium $5.6 \mathrm{mEq} / \mathrm{L}$, chloride $100 \mathrm{mEq} / \mathrm{L}$, calcium $10.2 \mathrm{mg} / \mathrm{dL}$, phosphorus $2.3 \mathrm{mg} / \mathrm{dL}$, albumin $4.2 \mathrm{~g} / \mathrm{dL}$, and C-reactive protein $0.02 \mathrm{mg} / \mathrm{dL}$. Negative inflammatory response despite mild liver dysfunction was confirmed. Computed tomography (CT) of the abdomen showed no gallbladder wall thickening or inflammation involving the surrounding tissues. However, swelling of the gallbladder, high- and isodensity contents of the gallbladder appearing as biliary sludge, and high-density stone in the gallbladder neck were observed (Fig. 1a). He was hospitalized for suspected acute cholecystitis.

Blood tests on the second day of hospitalization revealed that his levels of total bilirubin, aspartate aminotransferase, and alanine aminotransferase had increased to $3.4 \mathrm{mg} / \mathrm{dL}$, $351 \mathrm{IU} / \mathrm{L}$, and $369 \mathrm{IU} / \mathrm{L}$, respectively. Therefore, obstructive jaundice was suspected and magnetic resonance imaging was conducted. T2-weighted imaging showed low-intensity contents expanded to include a wide area from the common bile duct to the cystic duct and gallbladder neck. On magnetic resonance cholangiopancreatography, the common bile duct was not drawn (Fig. 1b). The patient was suspected of having obliterative cholangitis of the common bile duct due to biliary sludge or hematoma and was transferred to the hospital for intensive treatment.

Physical examination at the time of hospital transfer revealed that the abdomen was flat and soft. The patient showed no sign of peritoneal irritation, though he had mild tenderness. Endoscopic retrograde cholangiopancreatography (ERCP) revealed clotting from the duodenal papilla (Fig. 2a). After cannulation of the bile duct, old blood and pus began to flow from the mammary papilla. On cholangiography, a defect of the common bile duct was observed (Fig. 2b) and the gallbladder and common bile duct seemed to be filled with blood clots. Compression on cholangiography was minimized to prevent exacerbation of bleeding, and an endoscopic nasobiliary drainage (ENBD) tube was placed. The bile was cultured and no bacteria were found. Since bleeding from the ENBD tube persisted, abdominal CT was conducted 2 days after hospitalization, but no clear bleeding source was found. Bleeding improved 3 days after hospitalization. Cholangiography via the ENBD tube showed no calculi or 
blood clots in the common bile duct. After his liver function had improved, the patient underwent laparoscopic cholecystectomy under general anesthesia 9 days after hospitalization. Clots were found in the lumen of the gallbladder, and subserosal bleeding was observed (Fig. 3). His sample revealed that the gallbladder was filled with blood clots and stones, and bleeding from partial ulceration of the mucosa was suspected. According to the pathologic findings, there were multiple hemorrhagic erosions on the mucosal side. On the day following the procedure, it was confirmed that there was no abnormality in the bile duct on cholangiography via the ENBD tube, and the tube was removed. Before hospitalization, heparin sodium had been used as an anticoagulant drug in dialysis. Until his condition stabilized following the procedure, nafamostat mesylate was used to prevent rebleeding. His postoperative course was uneventful and he was discharged on day 19 after the procedure. Currently, he is being followed at the hospital where he receives maintenance dialysis.

\section{Discussion}

Hemorrhagic complications may occur in patients on dialysis, and uremic bleeding is a well-known clinical condition in such patients. Uremic bleeding is associated with clinical features such as anemia, platelet dysfunction, comorbidities, urotoxia, blood platelet dysfunction, use of antiplatelet agents or anticoagulants, and patient age [3]. Although bleeding associated with chronic renal failure is clinically important, its assessment is difficult because dialysis affects platelet aggregation and coagulation cascade [4]. Causes of hemorrhage of the digestive tract in patients on dialysis include peptic ulcer (20-30\%), gastritis (20\%), telangiectasia of the stomach, duodenum, jejunum, or large intestine (20-30\%), duodenitis, and esophagitis [5]. However, bleeding from the gallbladder is very rare in patients on dialysis. Thus, this is a disease with low recognition that requires more attention for diagnosis.

Hemorrhagic cholecystitis is a rare disease. In 1948, Sandblom [6] first reported bleeding from the hepatobiliary system to the gastrointestinal tract as hemobilia. In 1979, Shah and Clegg [7] described hemobilia caused by cholecystitis as hemorrhagic cholecystitis. The characteristic symptoms of hemobilia include bleeding from the gallbladder, abdominal pain, jaundice, and gastrointestinal bleeding [1]. According to a report of 222 patients by Green et al. in 2001 [2], bleeding from the gallbladder was caused by iatrogenic factors, inflammation, tumor, injury, and other factors in approximately $65,13,7,6$, and $9 \%$ of patients, respectively. Cholelithiasis is well related to microbleeding from the gallbladder, and it has been reported that gallstone-related microbleeding accounts for $9 \%$ of hemobilia cases [8]. Calculi in the gallbladder may damage the mucosa directly, resulting in damage to the vessel walls [9]. It is also thought that increased pressure in the gallbladder due to acute cholecystitis may damage the gallbladder mucosa, resulting in damaged vessel walls and, ultimately, leading to bleeding $[10,11]$.

For the diagnosis of hemorrhagic cholecystitis, it is important to confirm the presence of bleeding and hematoma in the gallbladder in addition to findings of cholecystitis, such as swelling of the gallbladder and wall thickening. On CT, hematoma in the gallbladder is visualized as high-density fluid, while extravasation may be found in the arterial phase with contrast enhancement [12]. There is a report that the signal intensity of hematoma resembles that of skeletal muscle on T1-weighted imaging and is converted into remarkably low intensity on T2-weighted imaging [13]. Bleeding from the papilla of Vater is found in $30 \%$ of patients on ERCP [14]. In our patient, biliary sludge was suspected because isodensity contents of the gallbladder were observed on CT. T2-weighted imaging showed low-intensity con- 
tents expanded from the common bile duct to the cystic duct and gallbladder neck. Thus, common bile duct obstruction due to biliary sludge or hematoma was suspected. Since ERCP revealed clots from the papilla of Vater, it was judged that bleeding from the gallbladder flowed into the common bile duct, causing hematoma and leading to obstructive jaundice.

The goal of treatment for hemobilia is to improve hemostasis and flow of bile secretion. If hemodynamics are stable even after vigorous bleeding, decompression of the bile duct should be considered at first. For mild hemobilia, conservative treatment may be provided by correction of coagulation disorder and transfusion loading. In most cases, endoscopic treatment, radiologic intervention, or surgery is required [15]. ERCP plays an important role in the treatment of hemobilia. At first, flow of bile secretion is improved by removing the hematoma in the biliary tract, which leads to improvement of abdominal pain and jaundice. For hemobilia due to hemorrhagic cholecystitis, cholecystectomy should also be performed. It has been reported that gallstone-related hemobilia has a good prognosis. In our patient, hemodynamics were stable, and thus the pressure of the biliary tract was reduced by ERCP. After his symptoms and blood test results had improved due to decompression of the biliary tract, laparoscopic cholecystectomy was conducted. His sample revealed multiple hemorrhagic erosions on the mucosal side. As the cause of his condition, cholecystolithiasis, anticoagulant therapy in dialysis, and oral administration of antiplatelet agents seemed to be associated compositely.

In conclusion, we treated a patient on maintenance dialysis who developed obstructive jaundice due to hemorrhagic cholecystitis. Since patients on maintenance dialysis have various comorbidities, it may be difficult to grasp the disease condition. In addition, as they typically have a poorer condition than patients who do not receive dialysis, treatment delays may become severe. Although hemorrhagic cholecystitis is rare, it should be considered as a differential diagnosis for patients on dialysis who have acute abdominal symptoms.

\section{Statement of Ethics}

The patient provided written informed consent for publication of this report.

\section{Disclosure Statement}

The authors declare no conflict of interest.

\section{References}

Grove WJ: Biliary tract hemorrhage as a cause of hematemesis. Arch Surg 1961;83:67-72. Green MH, Duell RM, Johnson CD, Jamieson NV: Haemobilia. Br J Surg 2001;88:773-786.

Lai YC, Tarng DC: Hemorrhagic acalculous cholecystitis: an unusual location of uremic bleeding. J Chin Med Assoc 2009;72:484-487.

4 Herrero-Calvo JA, González-Parra E, Pérez-García R, Tornero-Molina F; Grupo de Estudio Español Sobre Anticoagulación en Hemodiálisis: Spanish study of anticoagulation in haemodialysis (in Spanish). Nefrologia 2012;32:143-152.

5 Janssen MJ, van der Meulen J: The bleeding risk in chronic haemodialysis: preventive strategies in highrisk patients. Neth J Med 1996;48:198-207.

6 Sandblom P: Hemorrhage into the biliary tract following trauma; traumatic hemobilia. Surgery 1948;24:571-586.

7 Shah VR, Clegg JF: Haemorrhagic cholecystitis. Br J Surg 1979;66:404-405. 
Shishida et al.: Hemorrhagic Cholecystitis in a Patient on Maintenance Dialysis

8 Yoshida J, Donahue PE, Nyhus LM: Hemobilia: review of recent experience with a worldwide problem. Am J Gastroenterol 1987;82:448-453.

-9 Bloechle C, Izbicki JR, Rashed MY, el-Sefi T, Hosch SB, Knoefel WT, Rogiers X, Broesch CE: Hemobilia: presentation, diagnosis, and management. Am J Gastroenterol 1994;89:1537-1540.

-10 Willemsen PJ, Vanderveken ML, De Caluwe DO, Wielliu IF: Hemobilia: a rare complication of cholecystitis and cholecystolithiasis. Case report. Acta Chir Belg 1996;96:93-94.

-11 Brady E, Welch JP: Acute hemorrhagic cholecystitis causing hemobilia and colonic necrosis. Dis Colon Rectum 1985;28:185-187.

$\$ 12$ Tavernaraki K, Sykara A, Tavernaraki E, Chondros D, Lolis ED: Massive intraperitoneal bleeding due to hemorrhagic cholecystitis and gallbladder rupture: CT findings. Abdom Imaging 2011;36:565-568.

$\$ 13$ Shimura T, Kojima T, Tsutsumi S, Yoshida T, Uchiumi H, Kuwano H: Gallbladder hematoma in a patient with hemophilia B, report of a case. Hepatogastroenterology 2000;47:939-941.

14 Shin KY, Heo J, Kim JY, Lee SJ, Jang SY, Park SY, Jung MK, Cho CM, Tak WY, Kweon YO: A case of hemocholecyst associated with hemobilia following radiofrequency ablation therapy for hepatocellular carcinoma. Korean J Hepatol 2011;17:148-151.

-15 Kim KH, Kim TN: Etiology, clinical features, and endoscopic management of hemobilia: a retrospective analysis of 37 cases. Korean J Gastroenterol 2012;59:296-302.
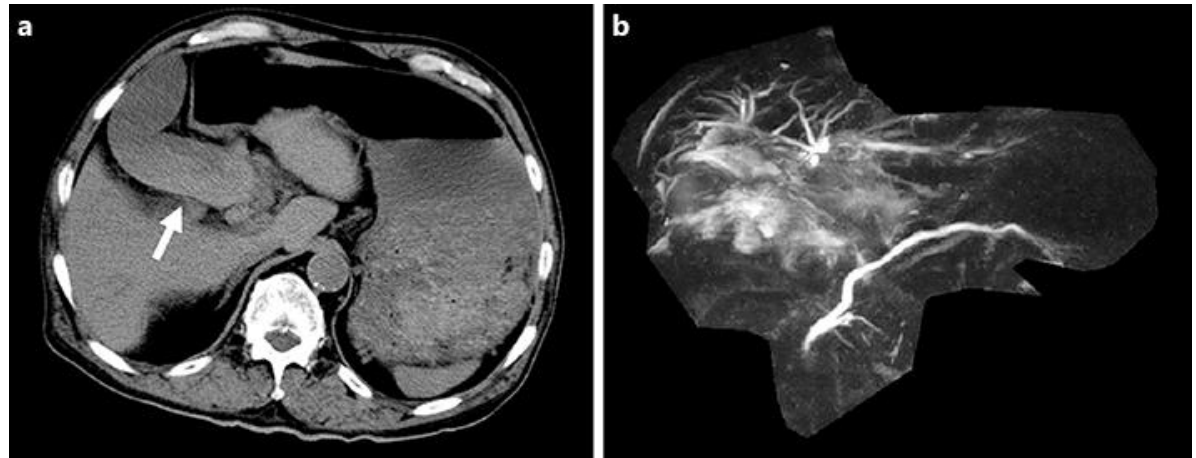

Fig. 1. Computed tomography and magnetic resonance cholangiopancreatography findings of hemobilia due to hemorrhagic cholecystitis. a On computed tomography, high- and isodensity contents of the gallbladder (arrow) were observed in a dialysis patient with hemorrhagic cholecystitis. b On magnetic resonance cholangiopancreatography, the common bile duct was not drawn. 


\section{Case Reports in Gastroenterology

\begin{tabular}{l|l}
\hline Case Rep Gastroenterol 2017;11:488-493 \\
\hline DOI: 10.1159/000479497 & $\begin{array}{l}\text { C 2017 The Author(s). Published by S. Karger AG, Basel } \\
\text { www.karger.com/crg }\end{array}$ \\
\hline
\end{tabular} \\ Shishida et al.: Hemorrhagic Cholecystitis in a Patient on Maintenance Dialysis}
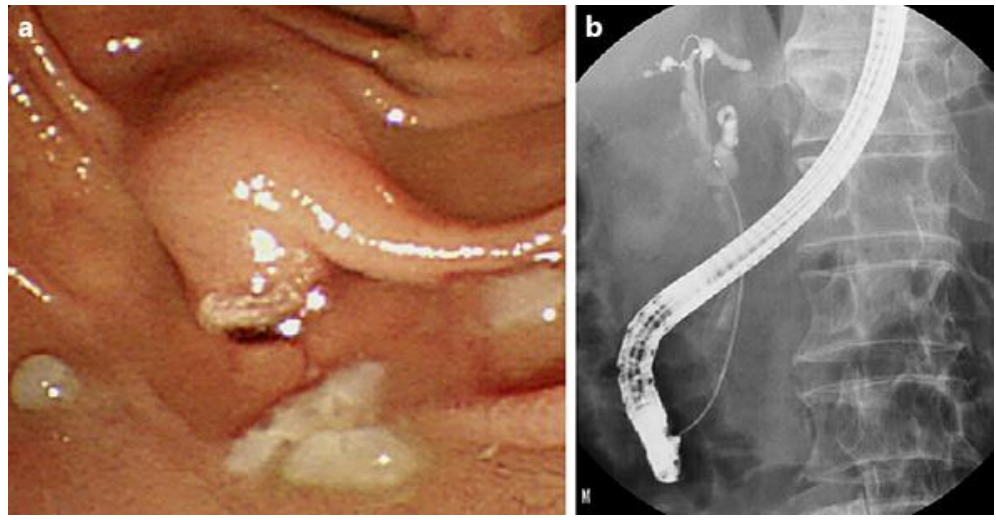

Fig. 2. Endoscopic retrograde cholangiopancreatography findings of hemobilia. a Clots and pus from the duodenal papilla. $\mathbf{b}$ Defect of the common bile duct.

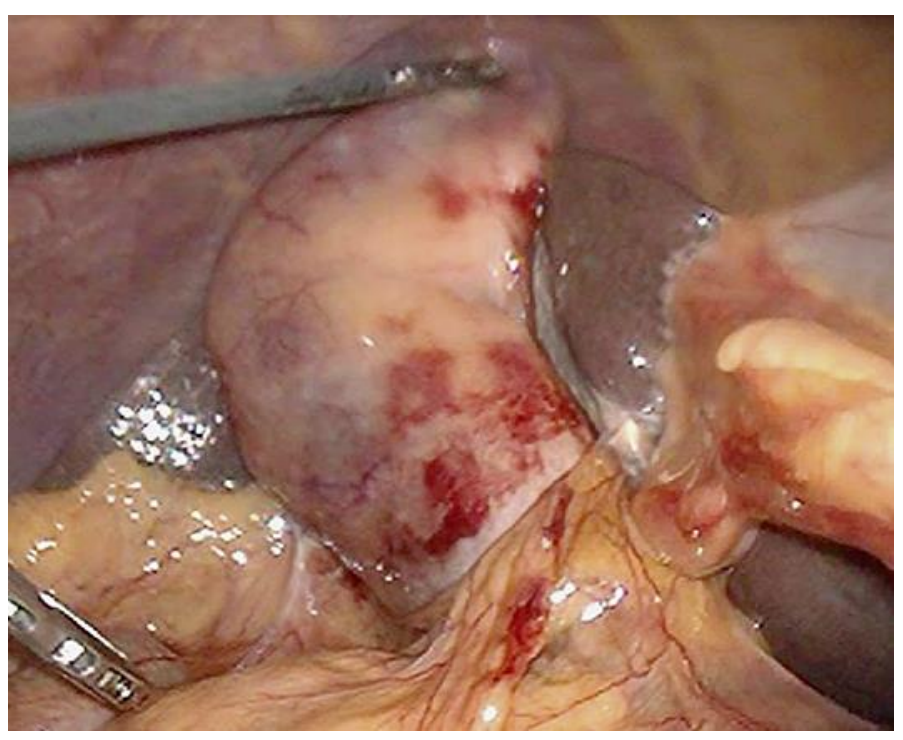

Fig. 3. Operative findings of hemorrhagic cholecystitis. 